\title{
GASTRO-ESOPHAGEAL REFLUX DISEASE BEFORE AND AFTER BARIATRIC SURGERIES
}

\author{
By
Said El-Seayd Ahmed El-Didamony Ahmed, Ahmed Ibrahim Shehata Kawashti and Ahmed Abd El Fattah Ahmed Mustafa

Department of General Surgery, Faculty of Medicine, Al-Azhar University, Egypt

Corresponding author: Said El-Seayd Ahmed El-Didamony Ahmed,

E-mail: drsaideldidamony@gmail.com

\begin{abstract}
Background: The relationship between obesity and gastro esophageal reflux disease (GERD) risk has been well established. Many authors suggest performing esophagogastroduodenoscopy (OGD) in all patients before bariatric procedures. On the other hand, many other investigators advocate a selective approach for asymptomatic patients. Laparoscopic Roux-en-Y gastric bypass (LRYGB) is considered by most experts the procedure of choice for the management of GERD in obese patients; however, the effect of LSG on GERD is still unclear.

Objective: To identify presences or absences of GERD in patients undergoing different types of bariatric surgery and the effect of this surgery on GERD status post operatively.

Patients and Methods: This study included forty successive morbidly obese patients who present to Surgery Department of Al-Azhar University Hospitals seeking for bariatric surgery, during the period from January 2018 to April 2020. Seventeen (42.5\%) of the patients were males, while twenty-three (57.5\%) were females. Upper endoscopy was performed preoperatively in all cases. Full history, physical examination and special investigations were taking, Patients was classified into laparoscopic sleeve gastrostomy (LSG) group (14 cases), laparoscopic greater curvature gastric plication (LGCGP) group, (3 cases), LRYGB group, (19 cases), and laparoscopic mini gastric bypass (LMGB) group, (4 case). OGD was done preoperatively in all patient and yearly postoperatively for two successive year.
\end{abstract}

Result: In LSG group (14 cases), post-operatively with follow up by OGD, there was five cases $(35.7 \%)$ have GERD sings and the rest of cases, nine cases $(64.3 \%)$ have normal esophageal mucosa. In LRYGB group, all patients have normal esophageal mucosa after operation. In LGCGP group, three cases, postoperatively with follow up by OGD, there was one case $(33.3 \%$ ) have GERD signs, and the rest of cases, two cases $(66.7 \%)$ have normal esophageal mucosa. In LMGB group, two case $50 \%$ improved in the 2nd year, one $(25 \%)$ improved from the 1 st year, and one case $(25 \%)$ has increased GERD symptoms, signs, and biliary reflux.

Conclusion: OGD should be done before bariatric procedures routinely or selectively, Laparoscopic Rouxen-Y gastric bypass (LRYGB) was considered the procedure of choice for the management of GERD in obese patients, However LSG still unclear on obese patient with GERD.

Key words: Morbidly obese patient, morbidly obese patient with GERD, OGD before and after bariatric surgeries, RYGBP in obese patient with GERD.

\section{INTRODUCTION}

Treatment for GERD is multifactorial and may involve dietary changes, lifestyle modifications, medication, surgery, or a

$\begin{aligned} & \text { combination of these, } \\ & \text { modifications and }\end{aligned}$
$\begin{aligned} & \text { diecommery } \\ & \text { recommendations }\end{aligned}$
individualized for each patient, loss of


weight, in overweight and obese subjects, stop smoking, Reduce alcohol consumption, raise the head of the bed, sleep in the left lateral decubitus position, avoid abundant food intake at least $2 \mathrm{~h}$ before going to bed at night, especially if the subject has nocturnal symptoms (Kinoshita et al., 2011 and Zanotti et al., 2016).

Gastro esophageal reflux disease (GERD) is a highly prevalent condition in morbid obese patients, the pathophysiology by which the increase in body mass index leads to increase in esophageal acid exposure is multifactorial, with the increased intra-abdominal pressure playing a major role. The majority $(60-70 \%)$ of patients with GERD symptoms will have normal gastroscopy (endoscopic negative reflux disease), however, patients who do have endoscopic evidence of esophagitis normally require long-term acid suppression (Sonnenberg, 2011).

Laparoscopic Roux-en-Y gastric bypass (LRYGB) is considered by most experts the procedure of choice for the management of GERD in obese patients, with excellent results in terms of reflux control and long-lasting weight loss (Shoar and Saber, 2017).

Laparoscopic sleeve gastrostomy (LSG) is a surgical approach to treat morbid obesity. It restricts the stomach's size to induce satiety and resects fundal ghrelin-producing cells to decrease appetite. LSG has become a very frequent procedure in bariatric surgery, due to its simplicity and efficacy compared to the gastric bypass procedure (AbouRached et al., 2014). However, the effect of LSG on GERD is still unclear, with conflicting evidence about pre-existing reflux control and the occurrence of de novo GERD after surgery (Oor et al., 2016).

The present work aimed to identify presences or absences of GERD in patient undergoing different types of bariatric surgery and the effect of this surgery on GERD status post operatively.

\section{PATIENTS AND METHODS}

This prospective study included forty successive morbidly obese patients who present to the surgery department of alAzhar university hospitals and Al-Ahrar Teaching Hospital seeking for bariatric surgery, in the period from January 2018 to April 2020.

The inclusion criteria were: Age range was $17 \sim 60$ years, BMI more than 40 or more than 35 with co-morbidity, Failure of non-surgical treatment, Absence of endocrinal or psychological disorders. The exclusion criteria were: Patients less than 17 years or more than 60 years, BMI less than 40 or less than 35 without comorbidities, Good response to non-surgical treatment, Presence of endocrinal or psychological disorders, Bad general condition of the patient.

\section{All patients were subjected to:}

- Full history and clinical examination with special symptoms of GERD heart burn, regurgitation, nausea, vomiting, bad breath, pain in chest and upper part of abdomen and difficulty swallowing.

- Laboratory investigations for preoperative evaluation including CBC, PT, liver functions, kidney functions, hormonal profile (FBS, Serum Cortisol, T3, T4, TSH) and 
coagulation profile (PT, PTT, PC and INR).

- Radiological investigations including chest X-ray, Abdomino-pelvic ultrasound, CT may be ordered in selected patients.

- Evaluation of the cardiac and respiratory condition in the form of Echocardiogram, and respiratory function tests.

All patients had a written informed consent of the different types of laparoscopic procedures of obesity, OGD was done in all patients preoperatively to identify the presences or absences of reflux disease. Prophylactic anticoagulant medications were given to all patients in the form of subcutaneous Clexane 0.5 unit/Kg/24. An ICU bed was reserved for all patients the night of operation with the decision of transfer left to the postoperative recovery assessment. According to the patient selection, all forty patients were divided in two groups as follows:

- Group (A) included patients who did not have GERD manifestations or positive finding of GERD during OGD preoperatively.

- Group (B) included patients who showed positive history or endoscopic finding of GERD during preoperatively OGD.

Group A patients according to history or finding of OGD, had a full range of selection of different types of bariatric surgeries conducted laparoscopic by the research team (laparoscopic gastric sleeve (LSG), mini gastric bypass (MGB), Rouxen-Y gastric bypass (RYGBP), greater curvature gastric plication (GCGP), while Group B patients had to choose between (Lap mini gastric bypass versus Lap Roux-en-Y gastric bypass).

Intraoperative leak test using methylene blue was done in all cases to check for leak. A suction drain is placed as needed.

After a standard postoperative course and discharge of patient from hospital, all patients were followed for up to two years on regular visits every month in the first 6 month then every three month in the second 6 month then every 6 month in the second year including patient complains, weight assessment, manifestations of vitamins and minerals deficiency as well as presences of GERD symptoms and requiring for medical treatment, OGD was done on yearly basis on patients during the follow up period up to two years, or farther radiological examination as required.

\section{Statistical Analysis:}

Patients' data were presented as frequency and percentage for categorical variables, mean and SD for numerical variables. Groups were compared by independent samples Student t-test and $\mathrm{X} 2$-test for numerical and categorical data, respectively. All data and statistical analyses were handled by statistical package for the social sciences (SPSS, IBM, SPSS Inc. Chicago, USA) computer package version 18.Maximum, minimum, and mean value considered. 


\section{RESULTS}

In the present study seventeen $(42.5 \%)$ of the patients were males while twentythree $(57.5 \%)$ were females. The patient's age ranged from 20 years to 50 years with a mean value of 35years. The lowest body mass index (BMI) was 37, while the highest was, 58.6 with a mean value of 47.8 , their height varied from $156 \mathrm{~cm}$ to $187 \mathrm{~cm}$ with a mean value of $171.5 \mathrm{~cm}$, while their weights ranged from $100 \mathrm{~kg}$ to $170 \mathrm{~kg}$ with a mean value of $135 \mathrm{~kg}$. (Table 1).

Table (1): Maximum, minimum and mean values of the age, BMI, Height, weight, and Gender (males and females)

\begin{tabular}{|c|c|c|c|c|c|c|}
\hline Parameter & \multirow{2}{*}{ Age } & \multirow{2}{*}{$\begin{array}{c}\text { Body Mass } \\
\text { Index }\end{array}$} & \multirow{2}{*}{ Height } & \multirow{2}{*}{ Weight } & \multicolumn{2}{|c|}{ Gender } \\
\cline { 5 - 8 } & & & & & Females & Males \\
\hline Mean & 35 & 47.8 & 171.5 & 135 & & \\
\hline Minimum & 20 & 37 & 156 & 100 & 17 & 23 \\
\hline Maximum & 50 & 58.6 & 187 & 170 & & \\
\hline
\end{tabular}

In Group A (twenty case) which included patient who do not have GERD manifestations or positive finding of GERD during OGD preoperatively. We performed laparoscopic sleeve gastrostomy (LSG) in fourteen (14) cases, laparoscopic greater curvature gastric plication (LGCGP) in three (3) cases and laparoscopic RYGBP in three (3) cases.
In Group B (twenty case) which included patient who have positive history or endoscopic finding of GERD during preoperatively OGD. We performed laparoscopic RYGBP in sixteen (16) cases and laparoscopic MGB in four (4) cases (Table 2).

Table (2): Number of cases according to types of operation.

\begin{tabular}{|c|c|c|c|c|c|}
\hline $\begin{array}{l}\text { Groups } \\
\text { Parameters }\end{array}$ & \multicolumn{3}{|c|}{ Group A } & \multicolumn{2}{|c|}{ Group B } \\
\hline Type of operation & LSG & LGCGP & RYGBP & RYGBP & MGB \\
\hline Number of cases & 14 & 3 & 3 & 16 & 4 \\
\hline
\end{tabular}

(laparoscopic sleeve gastrectomy( LSG), laparoscopic greater curvature gastric plication (LGCGP), laparoscopic Roux -enY gastric bypass ( RYGBP), laparoscopic mini gastric bypass (MGB) 

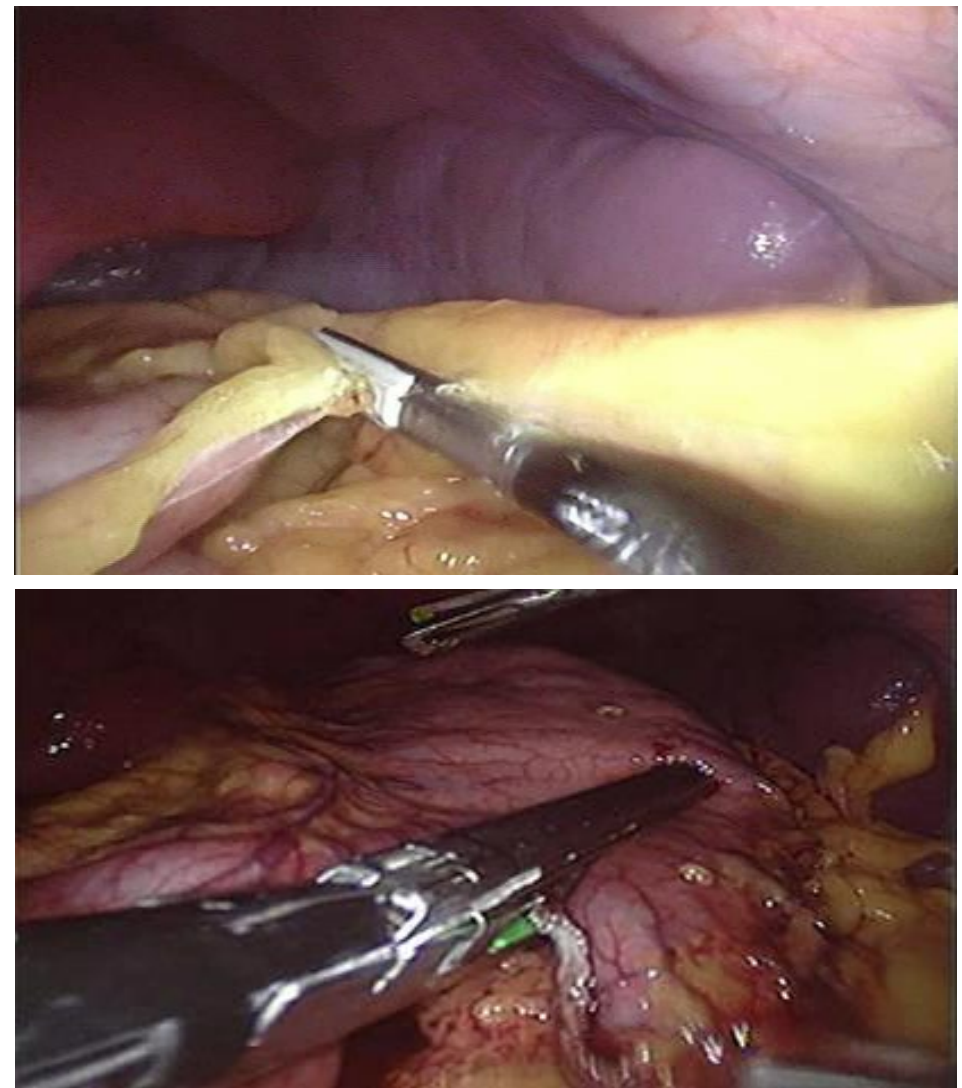

Figure (1): $\quad$ Steps of SG operation (upper), devascularization and (lower), stappling
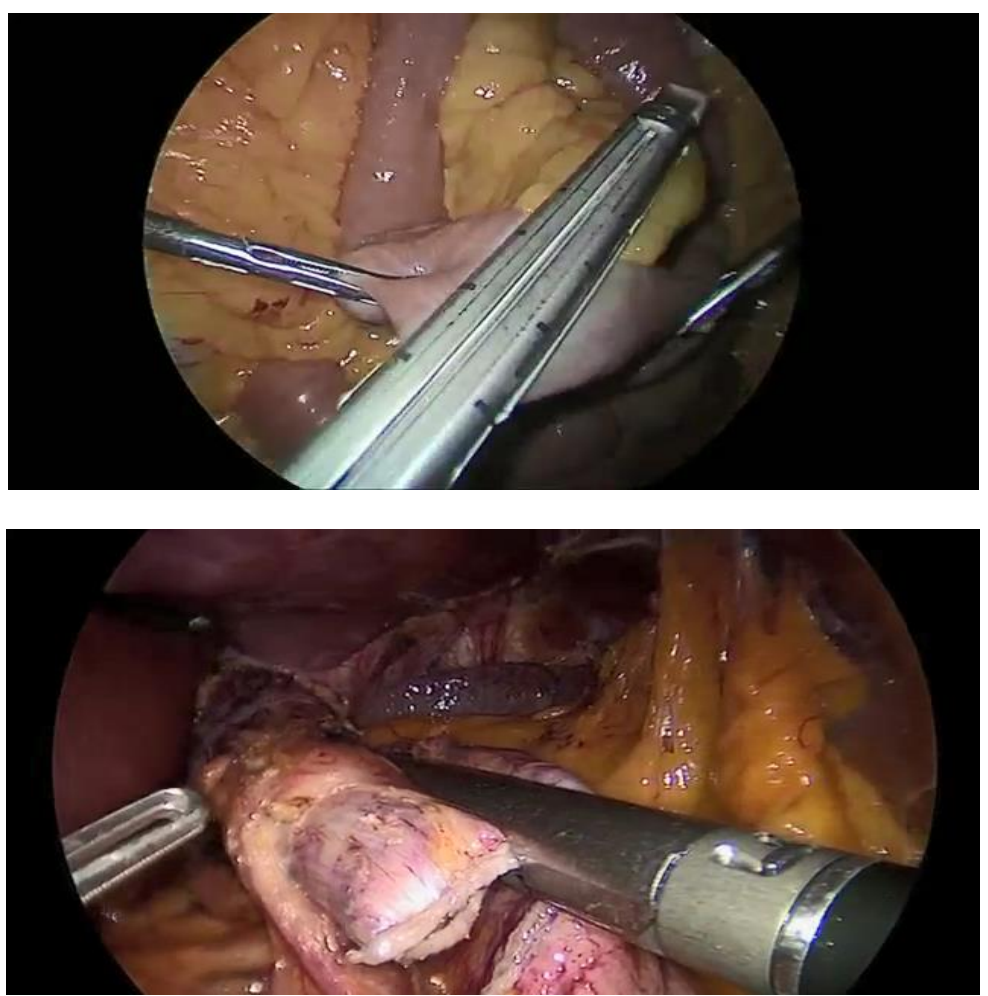

Figure (2): Steps of RYGBP the (upper) division of jejunum, and the (lower) creation of gastric pouch 

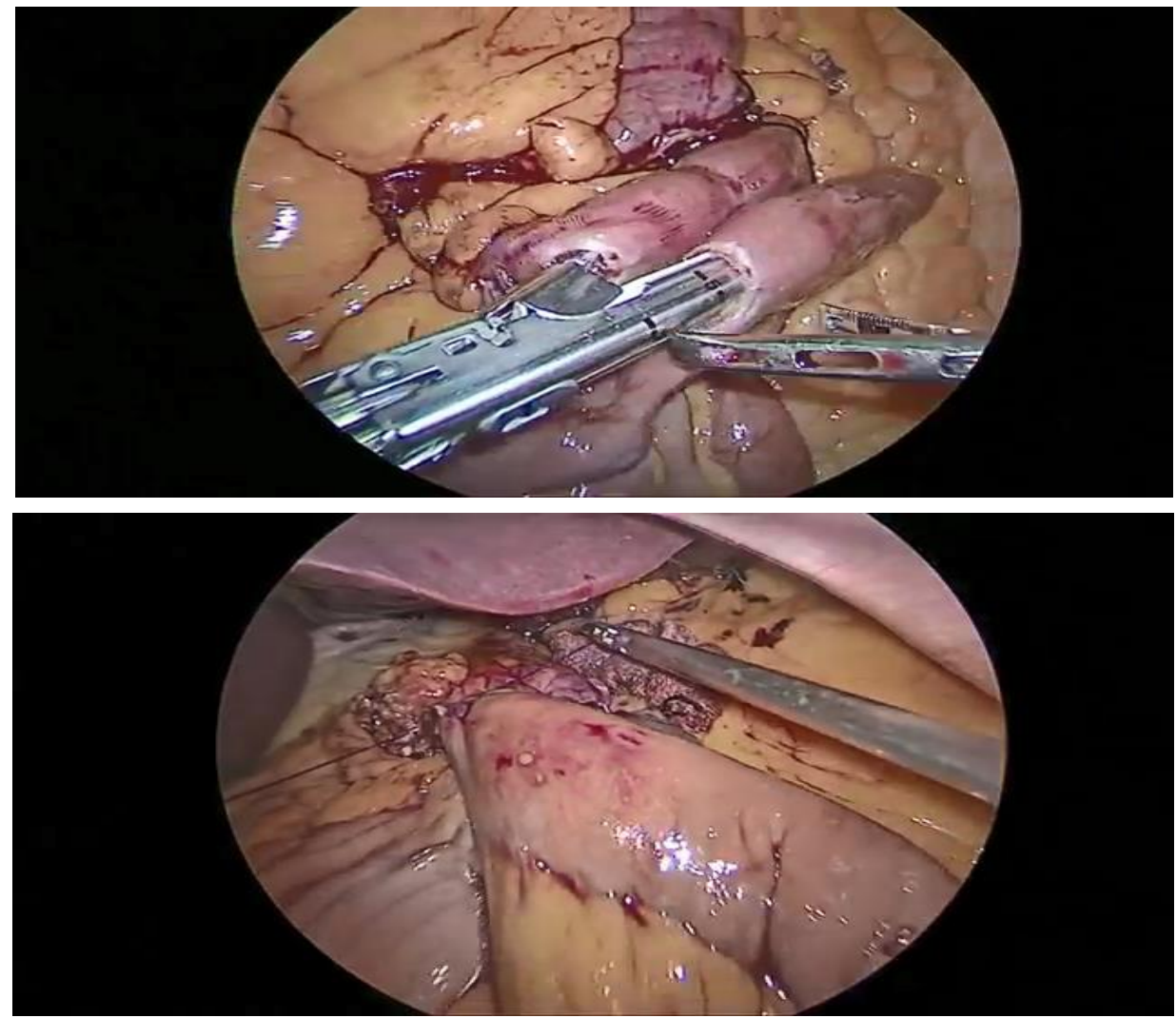

Figure (3): (Upper) jejunojejunostomy and (Lower) gastrojejunostomy

The operation time for sleeve gastrectomy was 110 minutes in the longest case, and 70 minutes in the shortest one with a mean value of 90 minutes, the operation time for greater curvature gastric plication was 90 minutes in the longest case, and 70 minutes in the shortest one with a mean value of 80 minutes, the operation time for RYGBP was 130 minutes in the longest case, and 100 minutes in the shortest one with a mean value of 115 minutes, and the operation time of MGB was 110minutes in the longest case and 80 minutes in the shortest one with a mean value of 95 minutes (Table 3).

Table (3): The comparative maximum, minimum \& mean values in the operative time in minutes \& the hospital stay in days between LSG, LGCGP, LRYGBP and LMGB

\begin{tabular}{|c|c|c|c|c|c|c|}
\hline \multirow{2}{*}{ Parameters } & \multicolumn{3}{|c|}{ Operation time(mint) } & \multicolumn{3}{c|}{ Hospital stay (day) } \\
\cline { 2 - 7 } Operations & Max & Min. & Mean & Max. & Min. & Mean \\
\hline LSG & 110 & 70 & 90 & 5 & 3 & 4 \\
\hline LGCGP & 90 & 70 & $\mathbf{8 0}$ & $\mathbf{4}$ & 2 & 3 \\
\hline LRYGBP & 130 & 100 & 115 & 13 & 5 & 9 \\
\hline LMGB & 110 & $\mathbf{8 0}$ & $\mathbf{9 5}$ & $\mathbf{6}$ & $\mathbf{4}$ & $\mathbf{5}$ \\
\hline
\end{tabular}

In follow up for weight loss post operatively, in LSG, the maximum weight loss $73 \mathrm{~kg}$, minimum weight loss $41 \mathrm{~kg}$, and the mean value $57 \mathrm{~kg}$, in LGCGP, the maximum weight loss $36 \mathrm{~kg}$, minimum weight loss $30 \mathrm{~kg}$, and the mean value 33 $\mathrm{kg}$, in LRYGBP, the maximum weight loss $90 \mathrm{~kg}$, minimum weight loss $58 \mathrm{~kg}$, and the mean value $74 \mathrm{~kg}$, and in LMGB, the maximum weight loss $70 \mathrm{~kg}$, minimum weight loss $50 \mathrm{~kg}$, and the mean value 60 kg. (Table 4). 
Table (4): Comparison of weight loss maximum, minimum and mean value according to type of operation (LSG, LGCGP, LRYGBP and LMGB)

\begin{tabular}{|c|c|c|c|c|}
\hline Type of operations & LSG & LGCGP & LRYGBP & LMGB \\
\hline Weight loss & 73 & 36 & 90 & 70 \\
Maximum. & 41 & 30 & 58 & 50 \\
Minimum. & 57 & 33 & 74 & 60 \\
\hline
\end{tabular}

In LSG group (14 case), all cases have not GERD manifestations and negative OGD signs of GERD preoperatively, but post-operatively with follow up by OGD, there was five cases have GERD sings from the 1st year post-operatively and the rest of cases have normal esophageal mucosa. In LRYGB group (19 cases), all patients who have GERD manifestations and positive OGD signs of GERD preoperatively became normal after operation. In LGCGP group (3 cases), all cases have not GERD manifestations and negative OGD signs of GERD preoperatively but post-operative with follow up by OGD there was one case have GERD signs from the 1st year postoperatively and the rest of cases have normal esophageal mucosa. In LMGB group (4 cases), all cases have GERD manifestations and positive OGD signs of GERD preoperatively, but post operatively, two cases improved in the 2nd year, one improved from the 1st year and one case has increase GERD symptoms, signs, and biliary reflux (Figure 4).

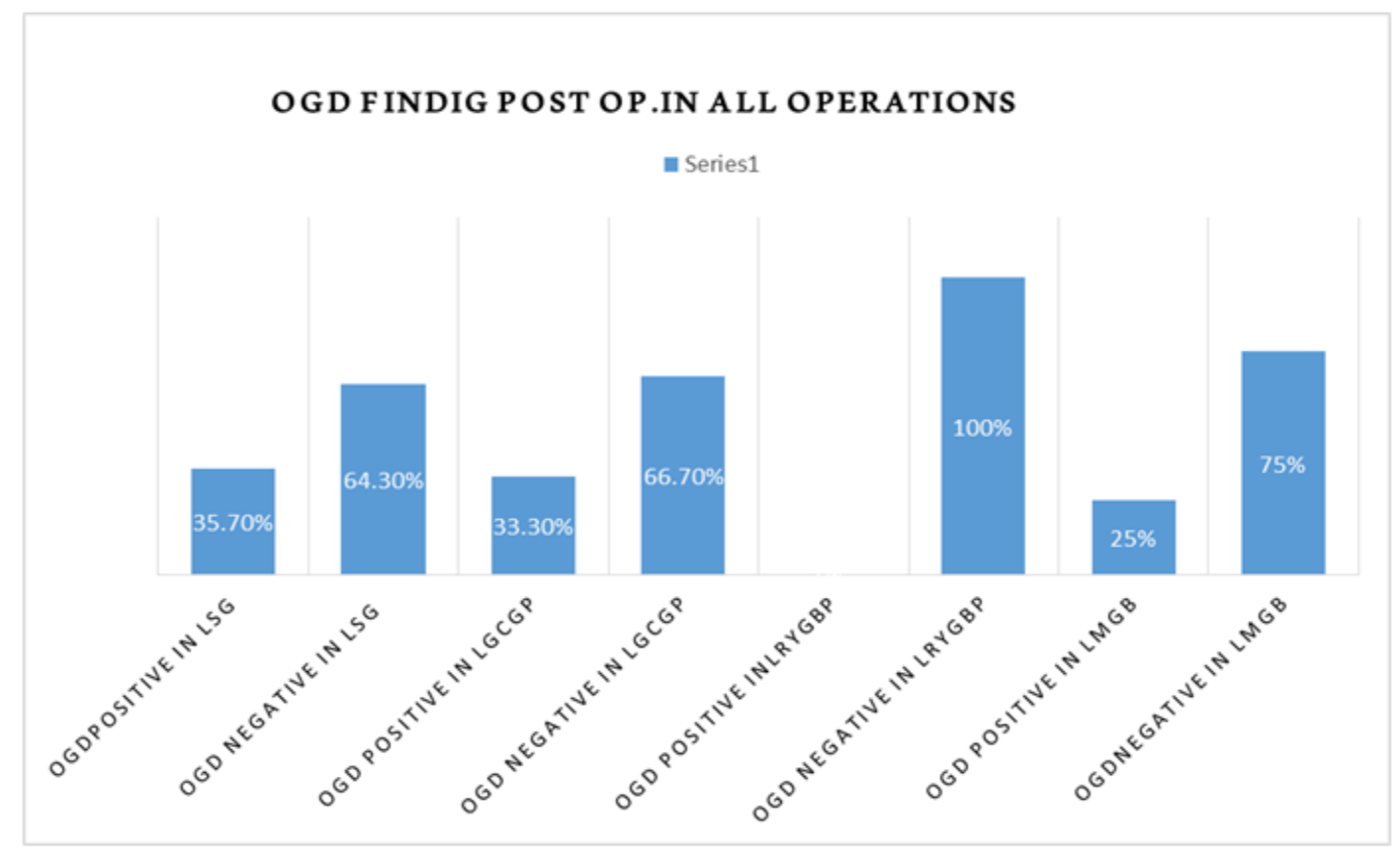

Figure (4): Percent of GERD post-operative according to types of operation 


\section{SAID E. A. EL-DIDAMONY et al.,}

\section{DISCUSSION}

In present study, we performed LRYGBP or MGB in obese patient associated with GERD, and LSG, LGCGP, LRYGBP or MGB in obese patients not associated with GERD. We chose LSG in bulky eater, BMI less than $50 \mathrm{Kg} / \mathrm{h} 2$ and RYGBP in sweaty eater or BMI more than $50 \mathrm{~kg} / \mathrm{h} 2$.

There was no clear consensus on the indications amongst those who did it selectively. This was particularly important in patients considered for LSG given the evidence linking it to worsening GERD and PPI dependence. The reason so much debate surrounds the issue is because significant GERD plays a major role in the choice of the bariatric procedure and the presence of peroperative reflux symptoms appears to be associated with post-operative GERD (Madhok et al., 2016).

Many authors suggest performing esophagogastroduodenoscopy (OGD) in all patients before bariatric procedures because of the lack of correlation between patient symptoms and OGD findings. On the other hand, many other investigators advocate a selective approach for asymptomatic patients because of the relatively weak clinical relevance of most lesions discovered on routine OGD along with the cost and invasiveness of OGD (Lee et al., 2017).

In the present study we performed routinely OGD preoperatively in all patients (40) patients whoever those patients have or have not GERD symptoms.

A majority of the studies were based on clinical evaluation, again with only a few utilizing endoscopy, 24-hour ambulatory $\mathrm{pH}$ studies. Esophageal manometry or contrast studies. They proposed caution with performing LSG due to the unquantified potential for worsening rates of GERD (Stenard and Iannelli, 2015).

Oor et al. (2016) reported clinical evaluation of GERD symptoms postoperatively, interestingly; the studies utilizing validated questionnaires had a risk difference of $4.3 \%$ postoperatively, while the eight studies with functional tests had paradoxical results. The pooled incidence of de novo GERD was $20 \%$. Given this, the authors made no definite conclusions, stating only that there appears to be an increased prevalence of GERD symptoms post LSG.

The anatomical and physiological effects on GERD post LSG have multifactorial explanations. In cases of de novo GERD, it is thought to be due to decreased gastric emptying, reduced LES pressure, blunting of the angle of His, decreased compliance and reduced volume of the stomach and increased intra gastric pressure secondary to the narrow gastric pouch and herniation of part of the sleeve into the mediastinum (Patti and Schlottmann, 2018).

Genco et al. (2017) advocated for endoscopic surveillance after LSG, irrespective of the presence of GERD symptoms. In view of these results, the improvement in GERD post LSG can be postulated to be anatomical (e.g., resection of acid-producing gastric fundus, accelerated gastric emptying and reduced gastric volume) or systemic (reduced intra-abdominal pressure due to weight loss). 
In the present study, we performed LSG in 14 case, only $35,7 \%$ developed GERD symptoms post-operatively from the 1st year and gave positive signs of GERD on OGD. The rest of cases $64,3 \%$ still normal post-operatively (have normal esophageal mucosa).

In patients with severe GERD symptoms post LSG, with resistance to maximal medical therapy, revisional surgery has been advocated: LRYGB is the procedure of choice in these patients. Cheung et al. (2014) conducted a systematic review of studies examining patients undergoing revisional bariatric surgery for failed weight loss. GERD was assessed in three studies and found that all patients had complete resolution of GERD symptoms with repeat LRYGB.

Parmar et al. (2017) found that $100 \%$ of patients reported improvement in GERD symptoms, and $80 \%$ were able to cease medications.

Holmberg et al. (2019) has contested this long-standing notion and postulated that the effect has been overstated. They defined postoperative reflux as residual or recurring symptoms of GERD with use of acid suppression medications for beyond six months postoperatively. Interestingly, they found GERD persisted in $48.8 \%$ of patients within two years of RYGB and persisted for up to 10 years after surgery. The strongest risk factor for postoperative GERD was high-dose preoperative acid suppression. In comparison, less than $10 \%$ of patients have persisting GERD after the traditional anti reflux surgery of fundoplication. Despite these findings, the authors concede that RYGB remains the most effect bariatric procedure in reducing GERD for the reasons.
In the present study, we performed LRYGBP in 19 case of obese patient associated with GERD signs and symptoms by OGD preoperatively. At a mean follow up of 24 months by OGD, all patients experienced a clinical improvement or no symptoms of GERD.

For obese patients suffering with GERD, sleeve gastrectomy (SG) has a complex relationship with GERD (Mahawar et al., 2013), where a majority of the patients report an improvement, but some experience deterioration and others notice de novo reflux. Similarly, though GERD usually improves with MGB, several authors have reported troublesome reflux symptoms requiring revision to either RYGB or Braun's anastomosis (Chevallier et al., 2015).

The authors observed that MGB led to a significant reduction in both esophageal acid exposure and in reflux episodes, whereas SG resulted in an increase in both. More interestingly, none of the MGB patients had any "weakly alkaline reflux" before or after surgery but SG patients experienced a significantly higher total, upright, and recumbent "weakly alkaline reflux" after surgery (Chevallier et al., 2013).

In present study, we performed MGB in 4 cases of obsess patient associated with GERD singes and symptoms by OGD preoperatively follow up by OGD was done for 24 months, $50 \%$ improved from $1^{\text {st }}$ year, $25 \%$ improved from the $2^{\text {nd }}$ year and $25 \%$ have biliary reflux.

\section{CONCLUSION}

OGD should be done before bariatric procedures routinely or selectively. Lifestyle modifications along with 
medications are considered the first line to treat obesity with new, but expensive, medications reaching the market. Laparoscopic Roux-en-Y gastric bypass (LRYGB) is considered the procedure of choice for the management of GERD in obese patients; the effect of LSG on GERD is still unclear, with conflicting evidence about pre-existing reflux control and the occurrence of de novo GERD after surgery.

\section{REFERENCES}

1. AbouRached A, Basile $M$ and EIMasri $H$. (2014): Gastric leaks post sleeve gastrectomy: Review of its prevention and management. World J Gastroenterol., 20(38): 13904-13910

2. Cheung D, Switzer NJ, Gill RS, Chan Y and Sung JJY. (2014): Revisional bariatric surgery following failed primary laparoscopic sleeve gastrectomy: a systematic review. Obes Surg., 24:1757-63.

3. Chevallier JM, Arman GA, Guenzi M, Rau C, Bruzzi M, Beaupel N, Zinzindohoué $F$ and Berger A. (2015): One thousand single anastomosis (omega loop) gastric bypasses to treat morbid obesity in a 7-year period: Outcomes show few complications and good efficacy. Obes Surg., 25:951-8.

4. Genco A, Soricelli E, Casella G, Maselli R, Castagneto-Gissey L, Di Lorenzo $\mathrm{N}$ and Basso N. (2017): Gastroesophageal reflux disease and Barrett's esophagus after laparoscopic sleeve gastrectomy: a possible, underestimated long-term complication. Surg Obes Relat Dis., 13:56-64.

5. Holmberg D, Santoni G and Xie S. (2019): Gastric bypass surgery in the treatment of gastro-oesophageal reflux symptoms. Aliment Pharmacol Ther., 50:159-66.

6. Kinoshita $Y$, Adachi $K$, Hongo $M$, and Haruma K. (2011): Systematic review of the epidemiology of gastroesophageal reflux disease in Japan. J Gastroenterol., 46:1092103.

7. Lee J, Wong SK, Liu SY and Ng EK. (2017): Is preoperative upper gastrointestinal endoscopy in obese patients undergoing bariatric surgery manda- tory? An Asian perspective Obes Surg., 27: $44-50$

8. Madhok BM, Carr WR and McCormack C. (2016): Preoperative endoscopy may reduce the need for revisional surgery for gastro-oesophageal reflux disease following laparoscopic sleeve gastrectomy. Clin Obes., 6: $268-272$

9. Mahawar KK, Jennings N, Balupuri $S$ and Small PK. (2013): Sleeve gastrectomy and gastro-oesophageal reflux disease: A complex relationship. Obes Surg., 23:987-91.

10. Oor JE, Roks DJ, Ünlü Ç and Hazebroek EJ. (2016): Laparoscopic sleeve gastrectomy and gastroesophageal reflux disease: A systematic review and meta-analysis. Am J Surg., 211: 250-267.

11. Parmar CD, Mahawar KK, Boyle M, Schroeder N, Balupuri S and Small PK. (2017): Conversion of Sleeve Gastrectomy to Roux-en-Y Gastric Bypass is Effective for Gastro-Oesophageal Reflux Disease but not for Further Weight Loss. Obes Surg., 27:16518.

12. Patti MG and Schlottmann F. (2018): Gastroesophageal Reflux after Sleeve Gastrectomy. JAMA Surg., 153:1147-8.

13. Shoar S and Saber AA. (2017): Long-term and midterm outcomes of laparoscopic sleeve gastrectomy versus Roux-en-Y gastric bypass: a systematic review and meta-analysis of comparative studies. Surg Obes Relat Dis., 13:170-180.

14. Sonnenberg A. (2011): Effects of environment and lifestyle on gastroesophageal reflux disease. Dig Dis., 29:229-234.

15. Stenard F and Iannelli A. (2015): Laparoscopic sleeve gastrectomy and gastroesophageal reflux. World $\mathbf{J}$ Gastroenterol., 21:10348-57.

16. Zanotti D, Elkalaawy $M$, Hashemi $M$, Jenkinson A and Adamo M. (2016): Current Status of Preoperative Oesophago-GastroDuodenoscopy (OGD) in Bariatric NHS Units-a BOMSS Survey. Obes Surg., 26: 2257-2262. 


\section{إرتجاع المرى قبل وبعد جر احات السمنة}

سعيد السيد أحمد الديدامونى، أحمدابراهيم شحاته قوشتى، أحمد عبدالفتاح أحمد

\section{مصطفى}

\section{قسم الجراحة العامة، كلية الطب، جامعة الازهر}

\section{E-mail: drsaideldidamony@gmail.com}

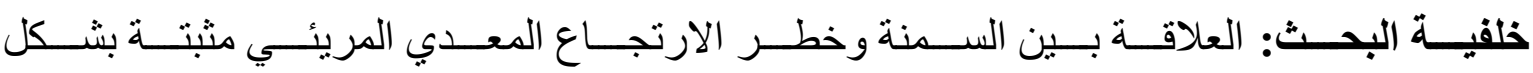

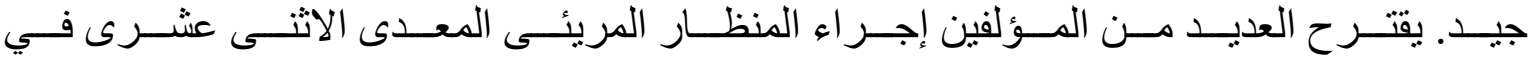

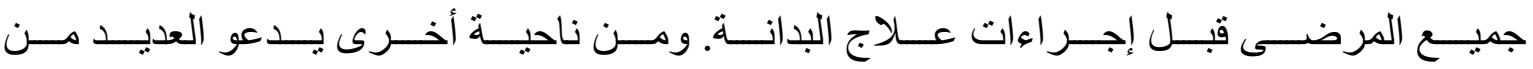

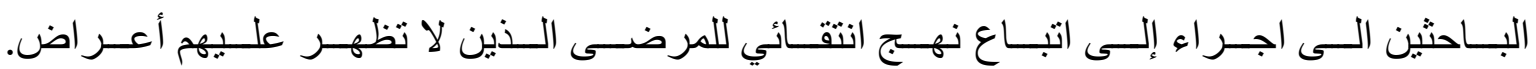

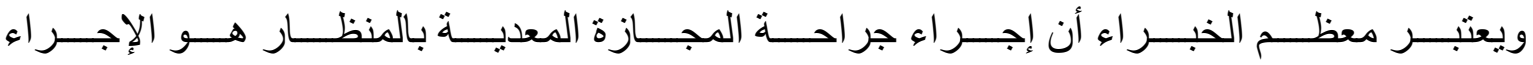

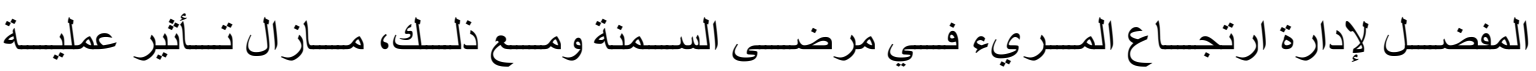

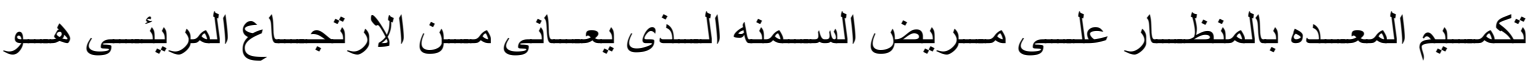

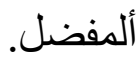

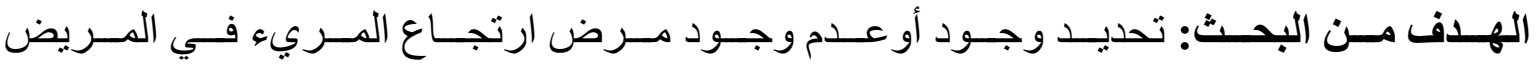

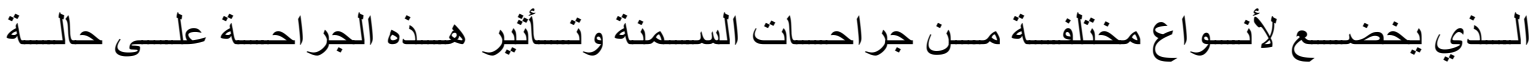

$$
\text { ارتجاع المريء بعد الجر احة. }
$$

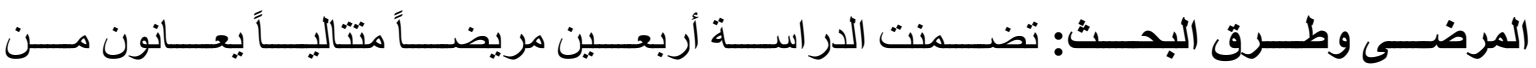

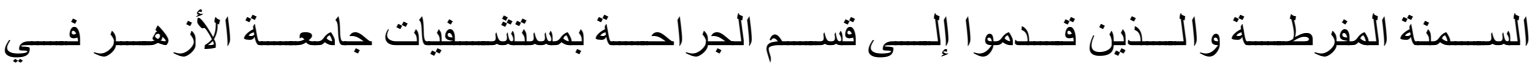

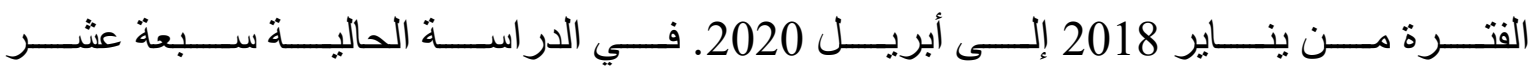

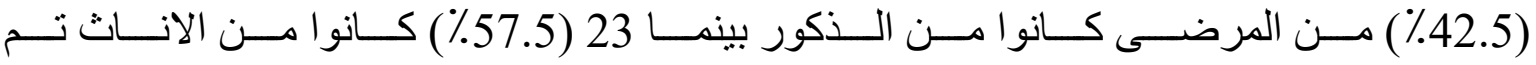

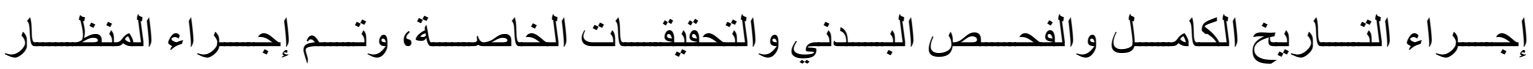

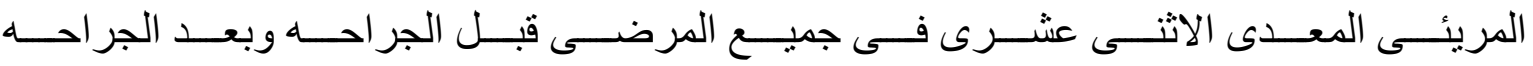
سنويا لمدة عامين منتالين.

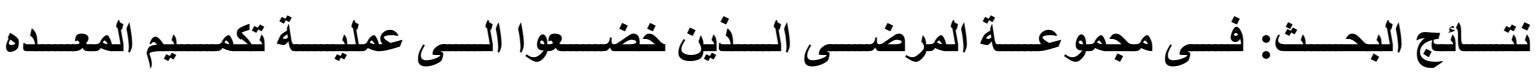

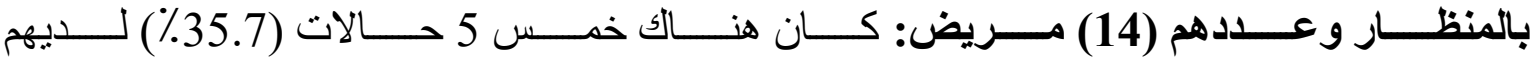

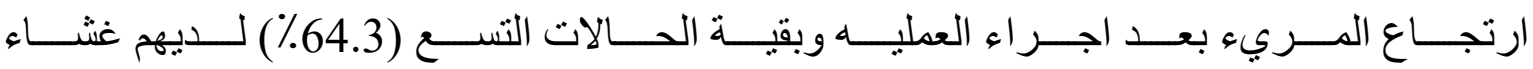




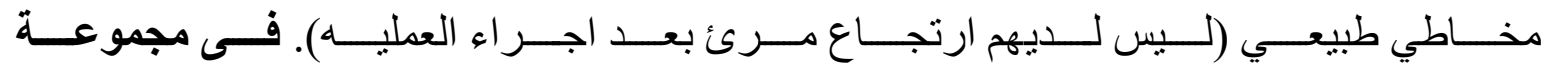

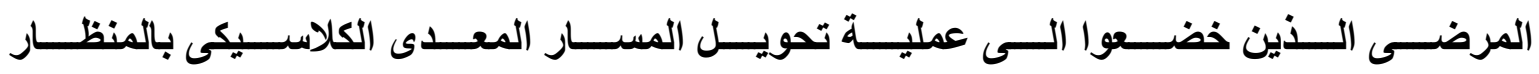

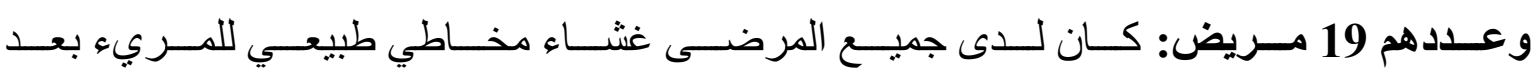

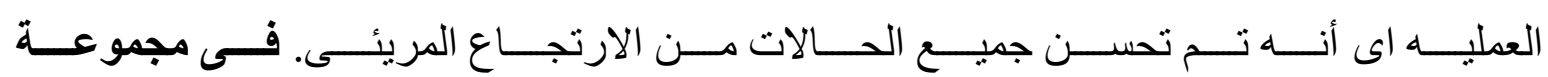

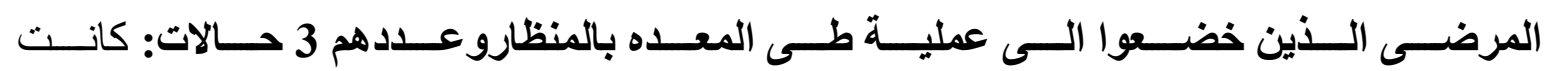

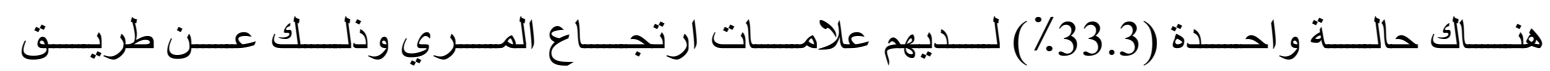

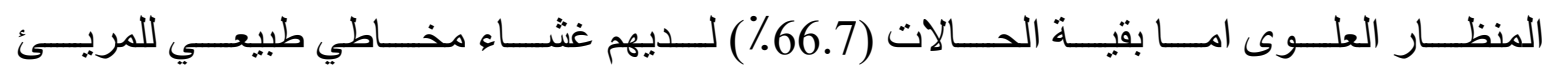

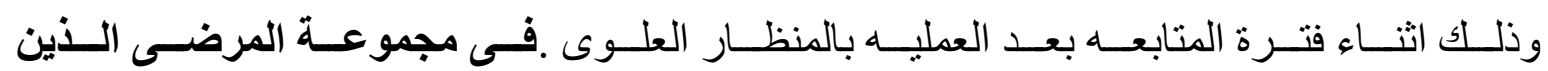

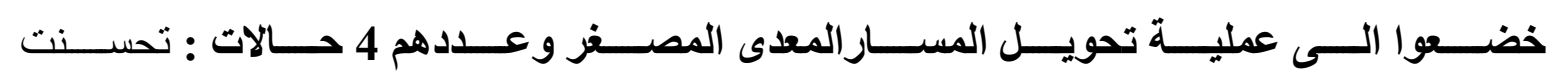

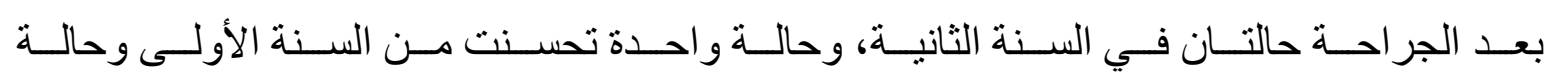
واحدة ذادت أعر اض ارتجاع المريء وعلامات الارتجاع الصفر اوي.

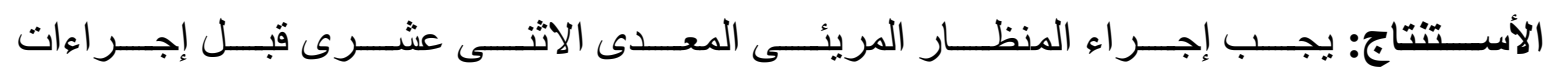

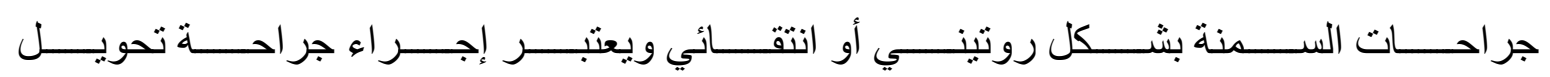

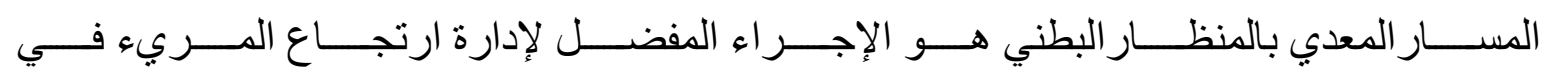

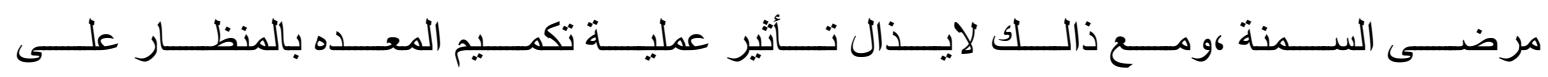
الارتجاع المريئى غير واضح بشأن مريض السمنه.

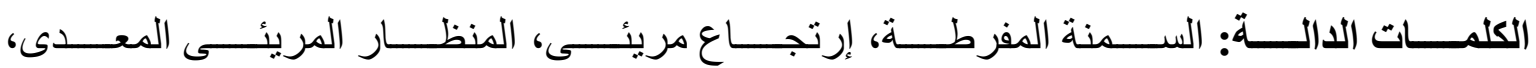
جر احات السمنة، تحويل مسار المعدة الكلاسيكى. 